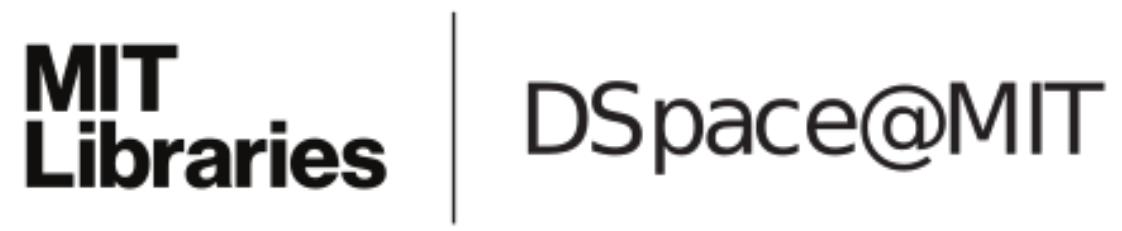

\author{
MIT Open Access Articles
}

FITMOS modeling and dynamic on-state characteristic evaluation

The MIT Faculty has made this article openly available. Please share how this access benefits you. Your story matters.

Citation: Li, Wei, William Page, and David J. Perreault. "FITMOS Modeling and Dynamic On-state Characteristic Evaluation." IEEE Energy Conversion Congress and Exposition 2010 (ECCE). 378385. (C) Copyright 2010 IEEE

As Published: http://dx.doi.org/10.1109/ECCE.2010.5618005

Publisher: Institute of Electrical and Electronics Engineers (IEEE)

Persistent URL: http://hdl.handle.net/1721.1/72469

Version: Final published version: final published article, as it appeared in a journal, conference proceedings, or other formally published context

Terms of Use: Article is made available in accordance with the publisher's policy and may be subject to US copyright law. Please refer to the publisher's site for terms of use. 


\title{
FITMOS Modeling and Dynamic On-state Characteristic Evaluation
}

\author{
Wei Li \\ Student Member, \\ William Page \\ David J. Perreault \\ IEEE Senior Member, IEEE
Laboratory for Electromagnetic and Electronic Systems
Research Laboratory of Electronics
Massachusetts Institute of Technology, Room 10-171
Cambridge, Massachusetts 02139
Email:fsrick@mit.edu

\begin{abstract}
This paper presents a study of the detailed characteristics of the new Floating Island and Thick Bottom Oxide Trench Gate MOSFET (FITMOS) developed at Toyota. FITMOS has tremendous potential for automotive applications due to its low on-resistance, improved temperature coefficient of resistance and low gate charge. During the study, the key characteristics of this novel FITMOS were investigated; a behavioral model was developed in SPICE for simulation and optimization purposes, and their applications in the design of automotive power electronics was explored. In this study, we also identify a previously unrecognized phenomenon in the FITMOS MOSFET. In particular, we show that the on-state resistance of the device depends on both frequency and peak $\mathrm{di} / \mathrm{dt}$ at a given frequency ${ }^{1}$. This dynamic on-resistance variation can have a significant application impact.
\end{abstract}

Index Terms-AC characteristics; capacitance modeling; DC-DC converters; FITMOS; I-V characteristics; optimization; on-resistance; reverse recovery; soft switching.

\section{INTRODUCTION}

Power electronics are essential to many automotive applications, and their importance continues to grow as more vehicle functions incorporate electronic controls. MOSFETs are key elements in automotive power electronic circuits. MOSFET characteristics can strongly affect circuit size, cost and performance. Advantages in MOSFET technology are thus of great importance to the advancement of automotive electronics.

The new Floating Island and Thick Bottom Oxide Trench Gate MOSFET (FITMOS) developed at Toyota has great potential for applications requiring devices with blocking voltages on the order of $60-100 \mathrm{~V}$. As described in [1] [2], the distinctive feature of the FITMOS is the use of floating islands and trench gates with a thick oxide layer at the bottom. This feature extends the breakdown voltage and maintains low on-resistance. In addition, the FITMOS also

1 These characteristics were observed in early-generation FITMOS devices. It is our understanding that these characteristics have been eliminated in the more recent generation of FITMOS devices. has low gate capacitance due to its floating island gate structure. As a result, with its low FOM [3], $\mathrm{R}_{\text {on }} \mathrm{Q}_{\mathrm{gd}}$, FITMOS is expected to have a very competitive performance with commercial power MOSFETs in the automotive power electronics space.

This paper presents modeling of early generation FITMOS devices, which includes capacitance modeling, I-V characteristic modeling, and body diode reverse recovery modeling. These results were used in the development and experimental evaluation of a FITMOS-based prototype DCDC converter design to validate the analytical results and provide a concrete demonstration of the impact of FITMOS transistors on power circuit designs. From studying the FITMOS-based converter, we demonstrate that the on-state resistance of the first-generation FITMOS devices shows a dependence on both switching frequency and peak di/dt. The dynamic on-resistance characteristic not only introduces discrepancies between static operation models and experimental results, but also affects the achievable design space and the suitable operating conditions of these new devices.

Section II presents the modeling result of the FITMOS. Section III reveals the AC characteristics of the on-resistance in the FITMOS and section IV concludes the paper.

\section{FITMOS MODELING}

Understanding the device parameters and their relations to loss mechanisms is important for utilizing the device better. For example, the gate capacitance determines the gating loss in hard switching; the output capacitance affects the switching loss and hence affects the optimum switching frequency; and the on-resistance is the key element for conduction loss. The modeling undertaken for FITMOS devices has three major parts: capacitance modeling; I-V characteristic modeling and body diode reverse recovery characteristic modeling. All the measurement data shown in this paper represent the averaged value among five sample devices. 


\section{A. Capacitance Modeling}

$\mathrm{C}_{\mathrm{OSS}}, \mathrm{C}_{\mathrm{ISS}}$ and $\mathrm{C}_{\mathrm{C}}$ are measured with an Agilent Impedance Analyzer $4395 \mathrm{~A}$ at $1 \mathrm{MHz}$ using 201 points with a frequency range of $100 \mathrm{kHz}$ to $10 \mathrm{MHz}$. From $\mathrm{C}_{\mathrm{OSS}}, \mathrm{C}_{\mathrm{ISS}}$ and $\mathrm{C}_{\mathrm{C}}$ :

$$
\begin{aligned}
& C_{O S S}=C_{D G}+C_{D S} \\
& C_{I S S}=C_{G D}+C_{G S} \\
& C_{C}=C_{G S}+C_{D S}
\end{aligned}
$$

we can extract out $\mathrm{C}_{\mathrm{GD}}, \mathrm{C}_{\mathrm{DS}}$ and $\mathrm{C}_{\mathrm{GS}}$ :

$$
\begin{aligned}
& C_{D G}=\frac{C_{O S S}+C_{I S S}-C_{C}}{2} \\
& C_{D S}=\frac{C_{O S S}-C_{I S S}+C_{C}}{2} \\
& C_{D G}=\frac{-C_{O S S}+C_{I S S}+C_{C}}{2}
\end{aligned}
$$

Capacitances $C_{D G}$ and $C_{D S}$ are functions of bias voltage. As a result, they need to be modeled as such. We use the junction capacitance equation to capture capacitance variation:

$$
C(V)=\frac{C_{j o}}{\left(1+\frac{V}{\phi}\right)^{m}}
$$

in which $\mathrm{C}_{\mathrm{jo}}$ is the zero-bias junction capacitance, $\mathrm{m}$ is known as the grading coefficient, and $\varnothing$ is the built-in junction potential. The values of the parameters in the equation are solved numerically based on least squares fit with the experimental data instead of physical modeling. The selected function models the capacitance accurately; the results are shown in Fig. 1 and Fig. 2.

\section{B. I-V Characteristic Modeling}

For I-V characteristic modeling, a behavioral model is used instead of physical model of the device since the traditional physical lateral MOSFET model may not model the vertical trench gate FITMOS properly. Moreover, the behavioral model is simpler and suitable for rapid simulation and calculation. There are two major operation regions for the MOSFET: triode region and saturation region.

In the triode region, the drain-source current $I_{d s}$ is inversely proportional to the on-resistance $R_{o n}$, and $R_{\text {on }}$ is modeled in a function of gate-source voltage $V_{g s}$ and threshold voltage $V_{t}$. For simplicity, and based on empirical observation, we treated the FITMOS device as being in triode region when $V_{d s}$ is less than $0.2 \mathrm{~V}$ since the current $I_{d s}$ is linearly proportional to $1 / R_{\text {on }}$ in this region. Fig. 3 shows the extracted $1 / R_{\text {on }}$ plot based on the slope of $I_{d s}$ versus $V_{d s}$ when $\mathrm{V}_{\mathrm{ds}}$ is less than $0.2 \mathrm{~V}$.

When the $\mathrm{V}_{\mathrm{gs}}$ is only slightly above the threshold voltage, $\mathrm{V}_{\mathrm{gs}}-\mathrm{V}_{\mathrm{t}}$ is small; $1 / \mathrm{R}_{\text {on }}$ strongly depends on $\mathrm{V}_{\mathrm{gg}}-\mathrm{V}_{\mathrm{t}} \cdot 1 / \mathrm{R}_{\text {on }}$ will not keep on increasing to a very large number as $\mathrm{V}_{\mathrm{gs}}-\mathrm{V}_{\mathrm{t}}$ continues to increase since $\mathrm{R}_{\text {on }}$ will saturate to its $\mathrm{DC}$ on-state value when $V_{\mathrm{gs}}$ is large enough. In order to model this transition accurately, we model the $1 / R_{\text {on }}$ separately for both small and large values of $\mathrm{V}_{\mathrm{gs}}$. The modeling functions are extracted based on the best least square fit with the experimental data. Fig. 4 shows the modeling result of $1 / R_{o n}$ over a large range of $\mathrm{V}_{\mathrm{gs}}-\mathrm{V}_{\mathrm{t}}$.

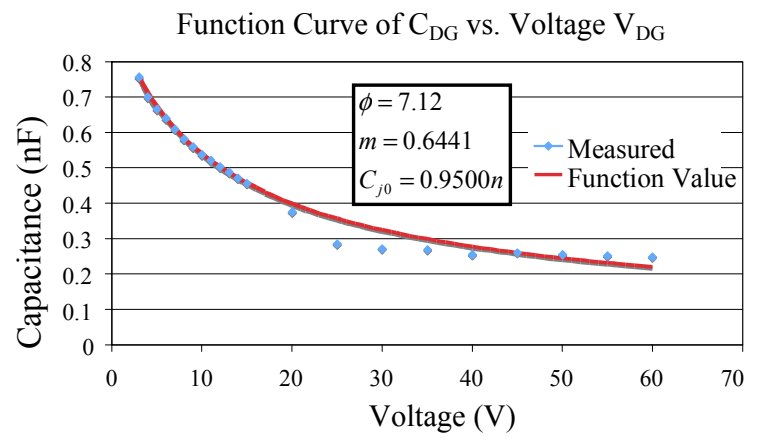

Fig. 1. The plot shows the $\mathrm{C}_{\mathrm{DG}}$ modeling. Data is collected with bias voltage from $3 \mathrm{~V}$ to $60 \mathrm{~V}$. When the bias voltage is below $3 \mathrm{~V}$, the device does not behave capacitively.

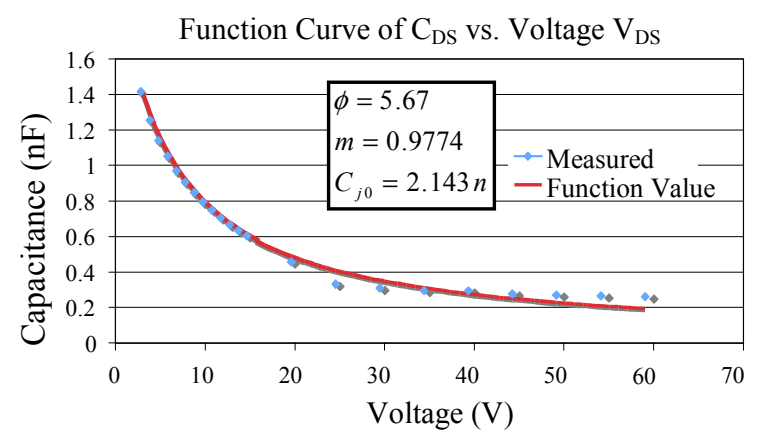

Fig. 2. The plot shows the $\mathrm{C}_{\mathrm{DS}}$ modeling. Data is collected with bias voltage from $3 \mathrm{~V}$ to $60 \mathrm{~V}$. When the bias voltage is below $3 \mathrm{~V}$, the device does not behave capacitively.

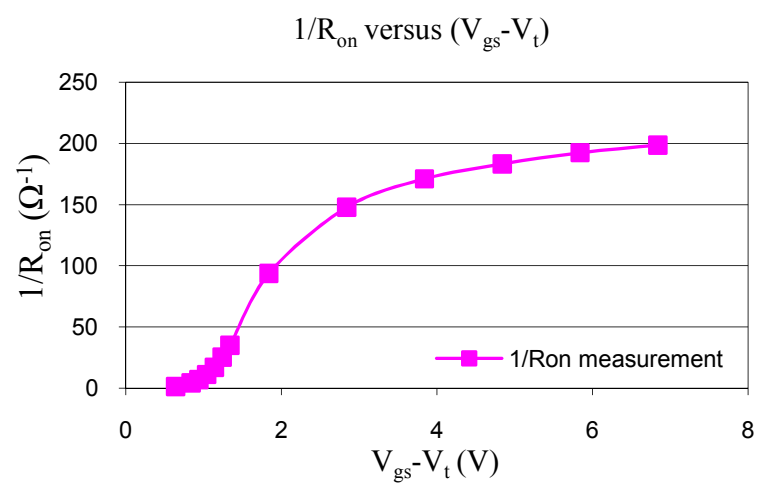

Fig. 3. $1 / R_{\text {on }}$ versus $\left(V_{g s}-V_{t}\right)$ plot. For large $V_{g s}, R_{o n}$ saturates to its $D C$ onstate value: $5 \mathrm{~m} \Omega$. 
(a) $1 / R_{\text {on }}$ in Triode Region for Small $V_{g s}-V_{t}$

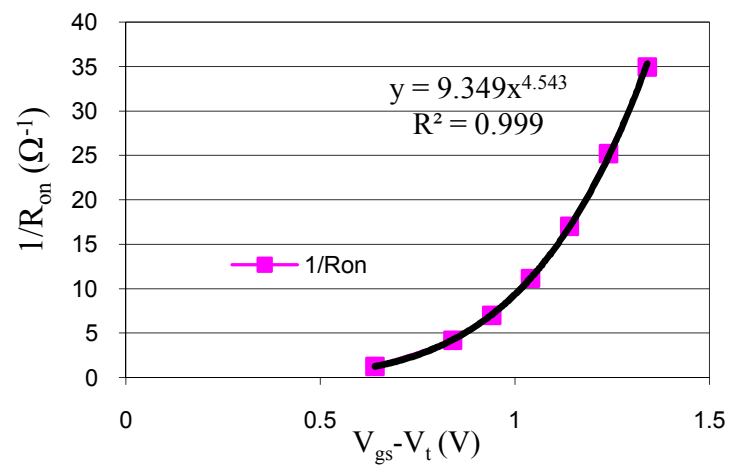

(b) $1 / R_{\text {on }}$ in Triode Region for Large $V_{g s}-V_{t}$

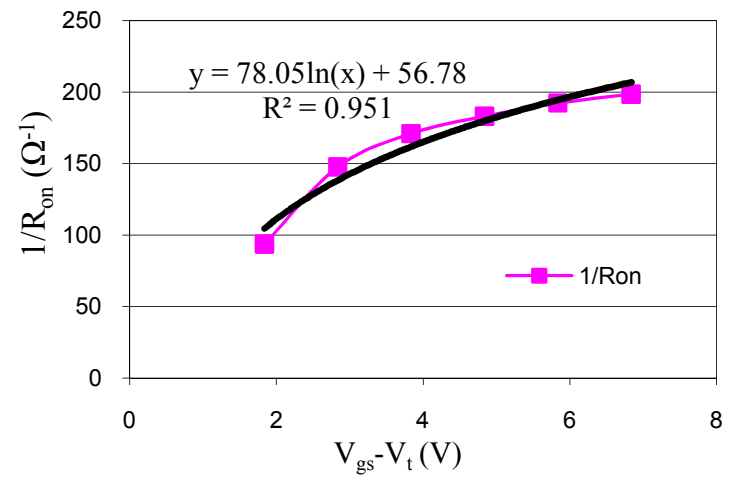

(c) $1 / R_{\text {on }}$ Modeling Comparison

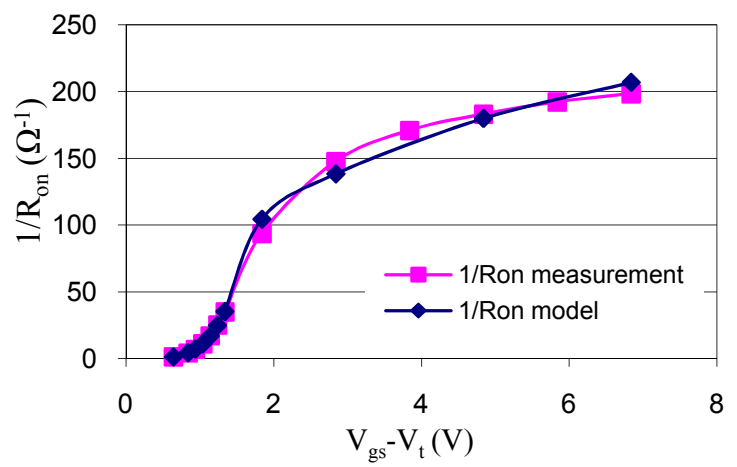

Fig. 4. These plots show the $1 / R_{\text {on }}$ modeling and result comparison. Plots (a) and (b) show the equation fit for $1 / R_{\text {on }}$ under small $V_{\mathrm{gs}}-V_{t}$ and large $V_{\mathrm{gs}}-\mathrm{V}_{\mathrm{t}}$ respectively. Plot (c) shows the overall result of the $1 / R_{\text {on }}$ model.

The overall $1 / \mathrm{R}_{\mathrm{on}}$ equation is (8)

$$
\frac{1}{R_{o n}}=\left\{\begin{array}{c}
9.35 \times\left(V_{g s}-V_{t}\right)^{4.54}, V_{g s}-V_{t}<1.67 \\
78.05 \times \ln \left(V_{g s}-V_{t}\right)+56.78, V_{g s}-V_{t} \geq 1.67
\end{array}\right.
$$

From the result shown above in Fig. 4(c), the function models the experimental results very well. As a result, in triode region, the drain-source current $\mathrm{I}_{\mathrm{ds}}$ is modeled as linearly proportional to the drain-source voltage $\mathrm{V}_{\mathrm{ds}}$, with a slope of $1 / R_{\text {on }}$ that is a function of $V_{g s}$ and $V_{t}$ :
$I_{d s}=\frac{V_{d s}}{R_{o n}}=$

$$
\left\{\begin{array}{c}
9.35 \times\left(V_{g s}-V_{t}\right)^{4.54} \times V_{d s}, V_{g s}-V_{t}<1.67 \\
\left(78.05 \times \ln \left(V_{g s}-V_{t}\right)+56.78\right) \times V_{d s}, V_{g s}-V_{t} \geq 1.67
\end{array}\right.
$$

In the saturation region, the $\mathrm{I}_{\mathrm{ds}}$ is modeled with (10):

$$
K\left(V_{g s}-V_{t}\right)^{\alpha}+\lambda V_{d s}
$$

The variables $K, \alpha$ and $\lambda$ are extracted from the numerical fit from the measured data. The measured I-V curves and their equation fit are shown in Fig. 5.

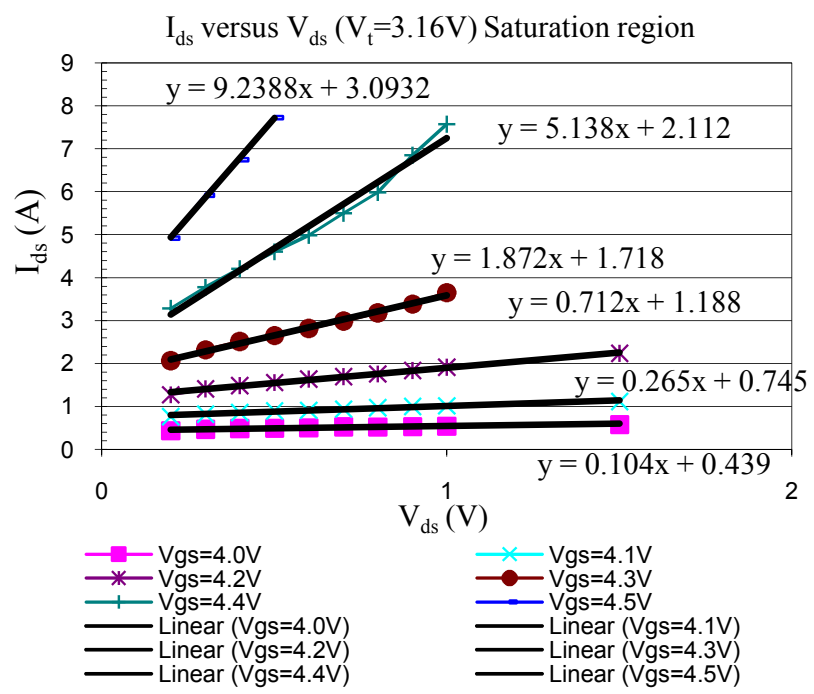

Fig. 5. Figure shows the measured I-V curves and their equation fit for the saturation region only.

$\mathrm{K}\left(\mathrm{V}_{\mathrm{gs}}-\mathrm{V}_{\mathrm{t}}\right)^{\alpha}$ is the intercept of the extended I-V trendline in saturation with the $y$-axis, which is $\mathrm{V}_{\mathrm{ds}}=0 . \lambda$ is the slope of the linear trendline fit for the I-V curve in saturation, which is also in a function of $\mathrm{V}_{\mathrm{gs}}-\mathrm{V}_{\mathrm{t}}$. The values of those variables are extracted as follows:

$$
\begin{aligned}
& \mathrm{K}=0.92 \\
& \alpha=4.34 \\
& \lambda=0.61\left(\mathrm{~V}_{\mathrm{gs}}-\mathrm{V}_{\mathrm{t}}\right)^{8.72}
\end{aligned}
$$

When the FITMOS operates in the saturation region, the $\mathrm{I}_{\mathrm{ds}}$ model is:

$$
I_{d s}=0.92 \times\left(V_{g s}-V_{t}\right)^{4.34}+0.61 \times\left(V_{g s}-V_{t}\right)^{8.72} \times V_{d s}
$$

After we combine the two operation regions, linear region and saturation, the complete final equation is shown in (12).

$$
\left\{\begin{array}{c}
I_{d s}= \\
\left\{\begin{array}{c}
9.35 \times\left(V_{g s}-V_{t}\right)^{4.54} \times V_{d s}, V_{g s}-V_{t}<1.67 \\
\left(78.05 \times \ln \left(V_{g s}-V_{t}\right)+56.78\right) \times V_{d s}, V_{g s}-V_{t} \geq 1.67 \\
V_{d s}<0.2
\end{array}\right. \\
0.92 \times\left(V_{g s}-V_{t}\right)^{4.34}+0.61 \times\left(V_{g s}-V_{t}\right)^{8.72} \times V_{d s}, V_{d s} \geq 0.2
\end{array}\right.
$$


Fig. 6 shows the comparison between our equation and experimental data. A very good match is observed in the figure, which is accurate enough for our SPICE simulation.

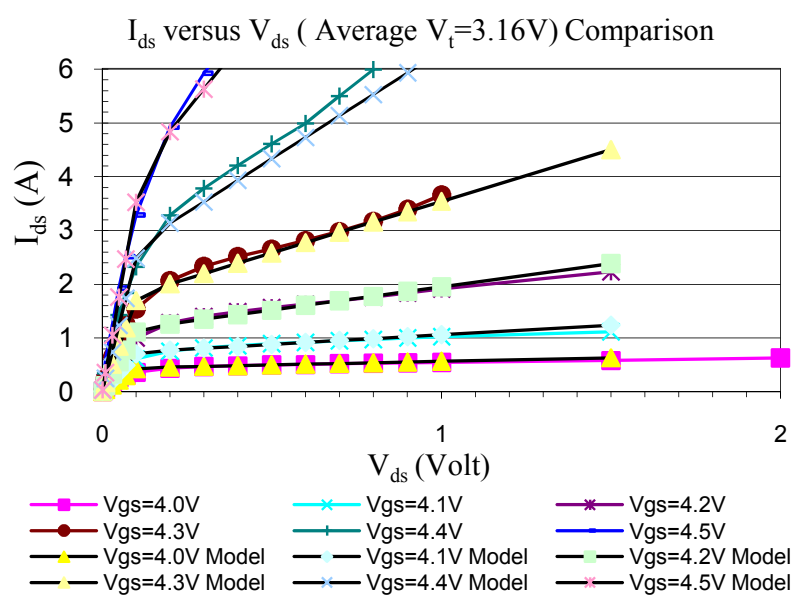

Fig. 6. This shows the measured FITMOS I-V characteristic and our behavioral model. Our model matched with the measurement very well.

\section{Reverse Recovery Modeling}

Reverse recovery of the body diode is a further important loss mechanism in the power MOSFET. This loss is due to the excess minority carrier storage in the body diode junction and is frequency dependent. It happens when the diode is rapidly switched from forward biased to reverse biased. The diode has to sweep out the excessive minority carriers in the junction before it can block a large negative voltage. So this behavior does not only add more loss from discharging the excess minority carriers, but also increases the switching losses. Capturing this power- and frequency-dependent loss can improve the accuracy of our SPICE device model. The reverse recovery measurement setup is shown in Fig. 7.

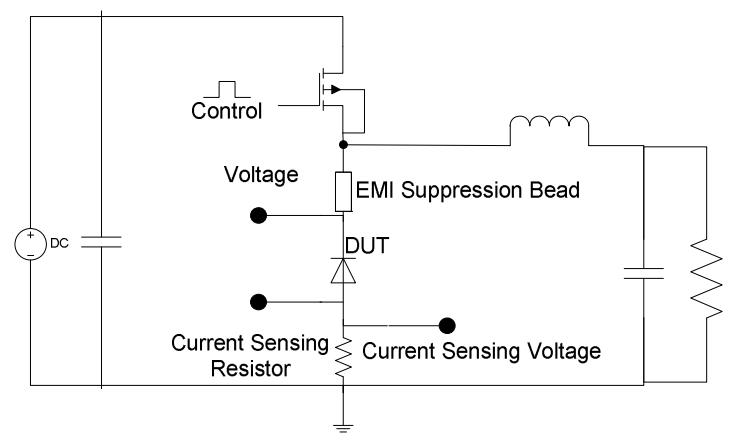

Fig. 7. This is the schematic of the measurement setup for reverse recovery. The body diode current is measured by a ground-referenced sensing resistor.

The measurement setup is a modified buck dc-dc converter. The gate and source of the low side MOSFET is shorted. When the control MOSFET is off, output current goes through the body diode in the low-side MOSFET. Once the high-side control MOSFET is turned on, the current will be drawn by the high-side MOSFET. The body diode in the low-side MOSFET is forced to turn off. During this transition, we can capture the reverse recovery behavior of the body diode. Parasitic ringing in the circuit can significantly affect the measurement result. As a result, this measurement is very sensitive to loop parasitics; extra care is taken to minimize the parasitic inductance in the measurement loop. For the current sensing, four $1.2 \Omega 0802$ surface mount resistors are connected in parallel, which gives a very flat resistive response up to $100 \mathrm{MHz}$. This bandwidth should be sufficient for us to obtain accurate measurement even accounting the high order harmonics in the current waveform. Furthermore, in order to eliminate the high frequency ringing for our measurement, an EMI suppression bead was used in the drain of the testing MOSFET device. For standard comparison, the di/dt of the diode falling current is set to be $100 \mathrm{~A} /$ us by controlling the gate resistance of the high-side MOSFET. The body diode reverse bias voltage is equal to the input voltage of the testing buck converter, which is $42 \mathrm{~V}$. The measurement is repeated for three different current settings by controlling the output power to be $100 \mathrm{~W}$, 200W and 400W.

The detailed characteristics are shown in table I:

TABLE I

FITMOS REVERSE RECOVERY CHARACTERISTICS

\begin{tabular}{cccccc}
\hline $\mathrm{I}_{f}$ & $\mathrm{I}_{r m}$ & $\mathrm{~T}_{a}$ & $\mathrm{~T}_{r r}$ & $\mathrm{Q}_{a}$ & $\mathrm{Q}_{r r}$ \\
\hline $3.4 \mathrm{~A}$ & $-0.9 \mathrm{~A}$ & $22 \mathrm{nS}$ & $104 \mathrm{nS}$ & $12.9 \mathrm{nC}$ & $67.6 \mathrm{nC}$ \\
$6.7 \mathrm{~A}$ & $-0.56 \mathrm{~A}$ & $31 \mathrm{nS}$ & $140 \mathrm{nS}$ & $12 \mathrm{nC}$ & $69.5 \mathrm{nC}$ \\
$9.1 \mathrm{~A}$ & $-0.53 \mathrm{~A}$ & $34 \mathrm{nS}$ & $167 \mathrm{nS}$ & $11.1 \mathrm{nC}$ & $68.5 \mathrm{nC}$ \\
\hline
\end{tabular}

$\mathrm{I}_{f}$ is the forward diode current; $\mathrm{I}_{r m}$ is the reverse peak current; $\mathrm{T}_{a}$ is the time for the diode current to drop from zero to negative maximum; $\mathrm{T}_{r r}$ is the reverse recovery time; $\mathrm{Q}_{a}$ is the charge for excessive minority carrier in the $\mathrm{T} a$ period only; $\mathrm{Q}_{r r}$ is the total reverse recovery charge.

A sample of reverse recovery behavior from our experimental results is shown in Fig. 8. From the plot, we can see that the diode cannot block reverse voltage until the excessive minority carriers are discharged.

The diode transit time $T_{t}$ in SPICE is often used to approximate the reverse recovery charge. To model the excessive minority charge in the junction [4] [5] [6], the minority carrier life-time constant is extracted base on our measurement by using (13):

$$
T_{t}=\frac{T_{a}}{\ln \left(1-\frac{I_{f}}{I_{r m}}\right)}
$$

$I_{f}$ is the forward diode current and $I_{r m}$ is the reverse peak current. $T_{a}$ is the time for the diode current to drop from zero to negative maximum. The average $T_{t}$ is calculated as $12.4 \mathrm{~ns}$ 
based on the data on Table I. The junction capacitance is modeled with the $\mathrm{C}_{\mathrm{DS}}$ capacitance.

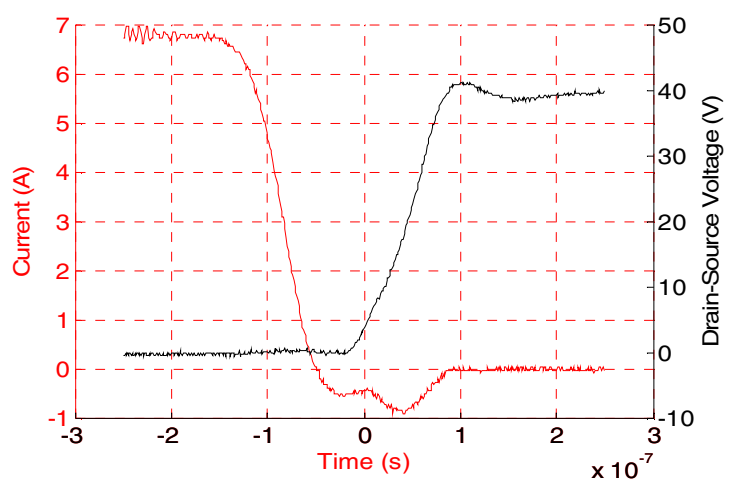

Fig. 8. This shows the measurement result sample for the reserve recovery behavior.

\section{Model Validation}

A prototype $14 \mathrm{~V}$ to $42 \mathrm{~V}$ synchronous boost converter has been developed for use in verifying the modeling results and for exploring the suitable applications of FITMOS devices. The converter operated in hard-switching mode at settable switching frequency. The output power of the converter can be up to $400 \mathrm{~W}$. A picture of the prototype converter is shown in Fig. 9

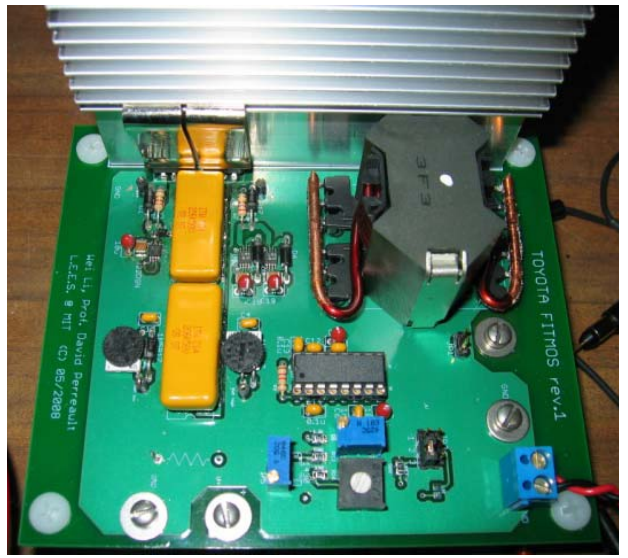

Fig. 9. This is the picture of the prototype converter. The heatsink is oversized for safety experiment purpose.

Overall, the model predicts the performance of the converter reasonable well; Fig. 10 shows the efficiency comparison between our FITMOS model and the experimental data for fixed frequency and various output powers.

From the plot, we can see that the simulation matches the experimental data over a wide output power range, $50 \mathrm{~W}$ to $300 \mathrm{~W}$. Below 300W, our model has no more than $2 \%$ error. But at powers approaching $400 \mathrm{~W}$, the converter suffers from
$\mathrm{V}_{\mathrm{ds}}$ saturation, and hence the efficiency decreases rapidly. This problem will be discussed in section III.
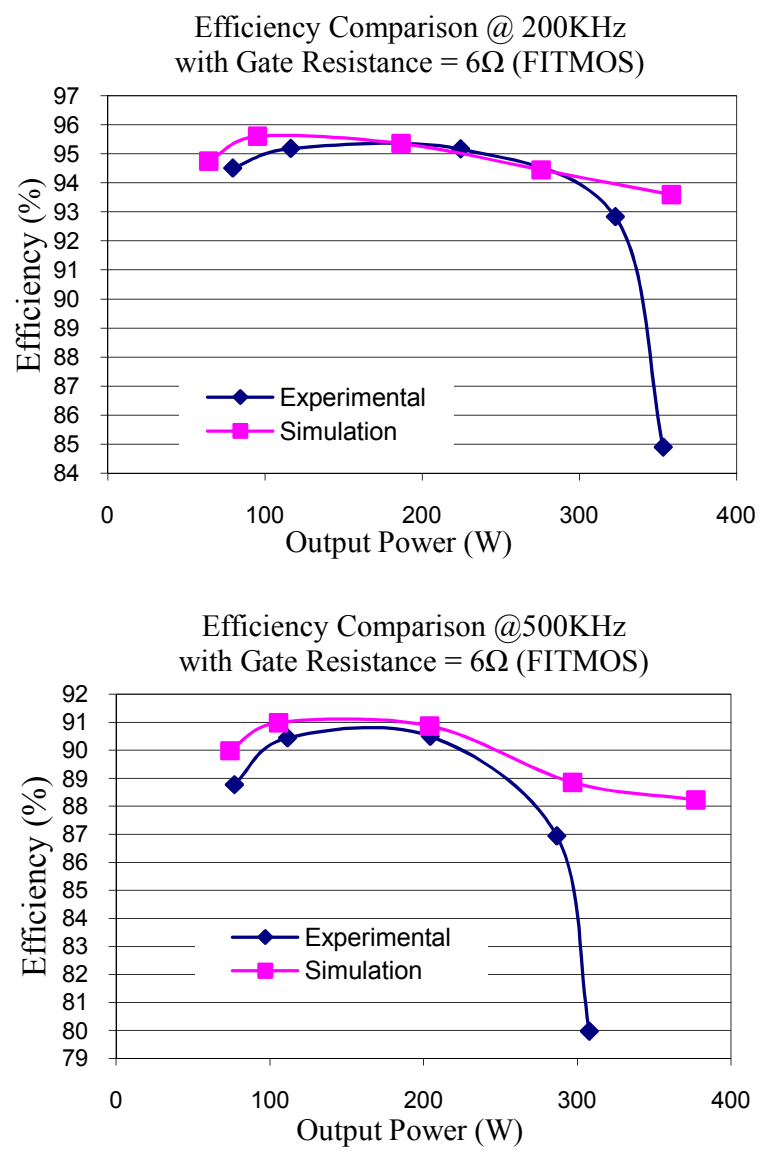

Fig. 10. The top plot shows the efficiency comparison between our FITMOS model with the experimental data at switching frequency of $200 \mathrm{kHz}$; the bottom plot shows the efficiency comparison at switching frequency of $500 \mathrm{kHz}$. An inductor value of $16 \mathrm{uH}$ is used.

Besides operating the converter in hard-switching mode, the converter is designed to operate under zero-voltage softswitching conditions at high di/dt. Under "resonant pole" soft-switching operation (with inductor current ripple ratio exceeding unity to enable ZVS switching), the overlap loss in the device is eliminated. As a result, the simulation predicts that there will be noticeable improvement on the converter performance. The simulation and comparison to experimental results are shown in Fig. 11.

The experiment result shows no performance improvement under soft-switching for FITMOS, which means there is extra loss mechanism under high current ripple conditions that is not captured in the model. These noticeable discrepancies between model and experiment are found at high power and high current ripple conditions. These are explained by the dynamic variation of on-resistance as described in section III. 


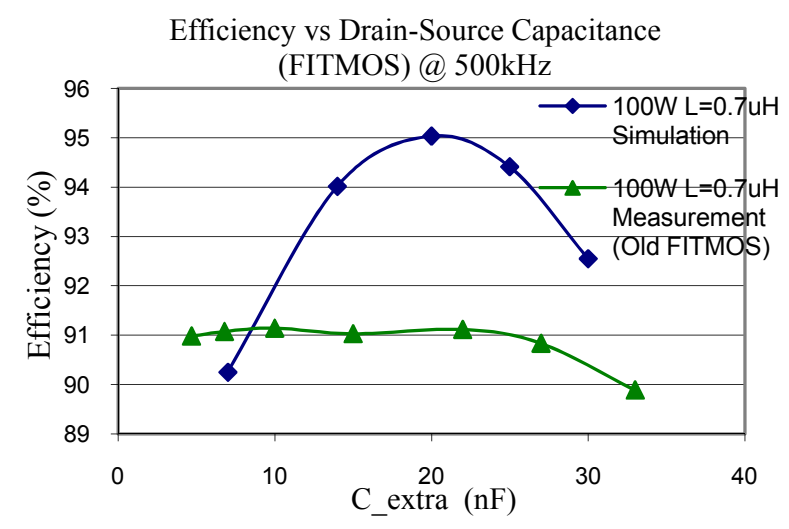

Fig. 11. Figure shows the converter soft-switching performance comparison between simulation and measurement result at $100 \mathrm{~W}$ output power with an inductor value of $0.7 \mathrm{uH}$. C_extra is the external drain source capacitance added across the lower device to achieve soft-switching.

\section{DYNAMIC ON-STATE CHARACTERISTICS}

From last section, we have observed that the converter efficiency drops significantly at high output power, over 300W in Fig. 10. After carefully studying the circuit behavior, an unexpected phenomenon is observed in the drain-source voltage $\mathrm{V}_{\mathrm{ds}}$ of the low-side MOSFET device for a time period after the device is turned on. As the drainsource current $I_{\mathrm{ds}}$ that is carried is increased to a certain level (e.g., by adjusting load resistance or input voltage at constant duty ratio), the drain-source voltage of FITMOS does not drop quickly to the normal low level $\left(\mathrm{R}_{\mathrm{ds}-o n} * \mathrm{I}_{\mathrm{ds}}\right)$ that is expected. Instead, it temporarily drops to a $2-3 \mathrm{~V}$ saturation level (or voltage step level) when the switch is turned on, and only drops to a low level as expected after a long delay time that depends on operating point. When $I_{d s}$ is increased sufficiently, this voltage step can extend across the whole on period for the switch. This situation significantly increases the loss in the device, and hence lowers the efficiency of the converter. Samples of this behavior are captured in Fig. 12.

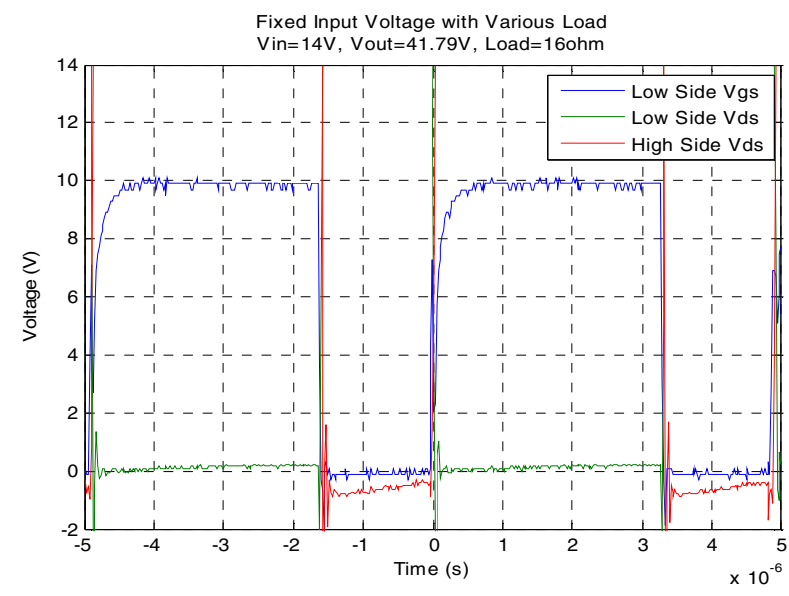

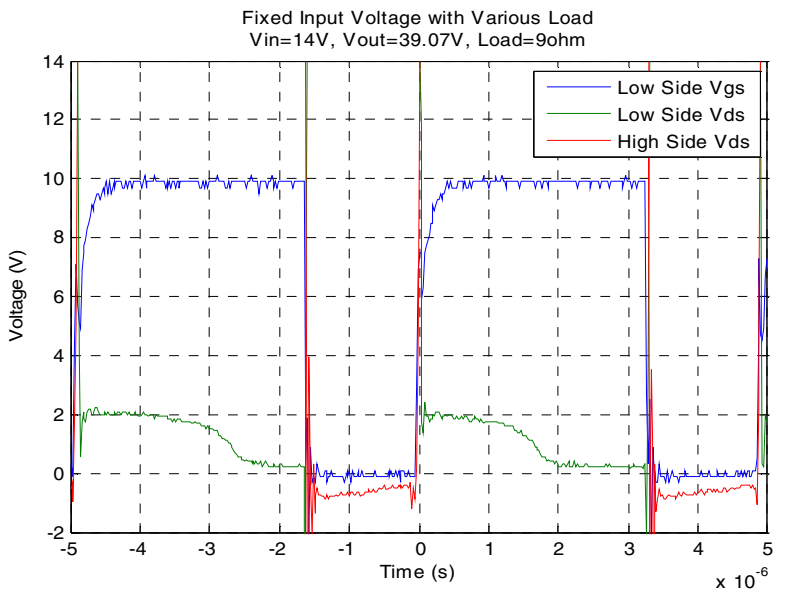

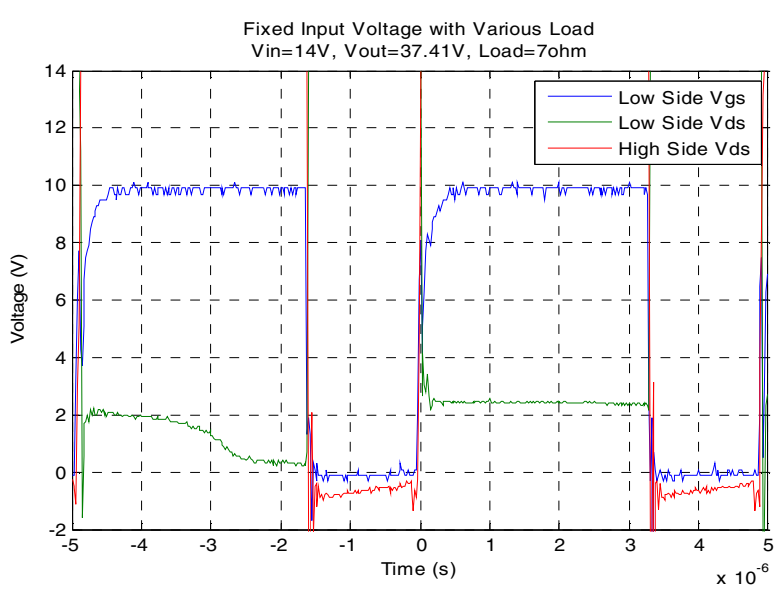

Fig. 12. Samples of the $V_{d s}$ saturation phenomena. The top figure shows no $\mathrm{V}_{\mathrm{ds}}$ saturation problem at low current. As the current increases, the Vds saturation problem starts to occur and get worse.

This $\mathrm{V}_{\mathrm{ds}}$ saturation problem was eliminated in a subsequent generation of FITMOS devices.

We also studied the discrepancies between model and experiment under high current ripple (di/dt) condition in softswitching. During examination, an increased $\mathrm{V}_{\mathrm{ds}}$ is observed during the on period when the device is experiencing high $\mathrm{di} / \mathrm{dt}$ in the drain-source current, even with the parasitic inductance effect extracted out. A sample of $\mathrm{V}_{\mathrm{ds}}$ measurement under high di/dt is shown in Fig. 13.

From Fig. $13, \mathrm{~V}_{\mathrm{ds}}$ of $0.31 \mathrm{~V}$ is measured. For $14 \mathrm{~V}$ input voltage, $42 \mathrm{~V}$ output voltage and load resistance of $20 \Omega$, the $\mathrm{dc}$ input current is about 6.3A. Under the soft-switching condition, the inductor current has 200\% peak-to-peak current ripple ratio. As a result, the peak current in the device is $2 \times 6.3=12.6 \mathrm{~A}$. Assuming the device temperature is $150^{\circ} \mathrm{C}$ (the actual device temperature is much less than $150^{\circ} \mathrm{C}$ ) and the on-resistance is about $8.5 \mathrm{~m} \Omega$, the calculated $\mathrm{V}_{\mathrm{ds}}$ should be $12.6 \mathrm{~A} \times 8.5 \mathrm{~m} \Omega=0.107 \mathrm{~V}$, which is much less than the measured value. We can also extract the package parasitic inductance effect on the $\mathrm{V}_{\mathrm{ds}}$ measurement. From the 
measurement, when the FITMOS is turned on, a ringing frequency of $18 \mathrm{MHz}$ is observed. Since we have a $10 \mathrm{nF}$ external capacitance across the drain and source of the device for soft-switching, which is much larger than the parasitic capacitance on the device, we can extract the parasitic inductance in the package from the ringing frequency:

$$
L=\frac{1}{C}\left(\frac{1}{2 \pi \times f_{\text {ringing }}}\right)^{2} \approx 7.94 n H
$$

The voltage offset caused by the parasitic inductance is

$$
V_{\text {offset }}=L \frac{d i}{d t} \approx 0.083 \mathrm{~V}
$$

At $500 \mathrm{kHz}$ switching frequency of $60 \%$ duty ratio with current ripple of $12.6 \mathrm{~A}, \mathrm{di} / \mathrm{dt}$ is calculated to be about $10 \mathrm{~A} /$ us. With the additional offset voltage from the parasitic inductance, the total calculated $\mathrm{V}_{\mathrm{ds}}$ is only $0.19 \mathrm{~V}$, which is over $30 \%$ less than the measured value. From the experimental converter measurements and MOSFET switching waveforms we observed and their comparison to simulation results, we believe that the effective FITMOS onresistance is dependent on the dynamics of the drain-source current.

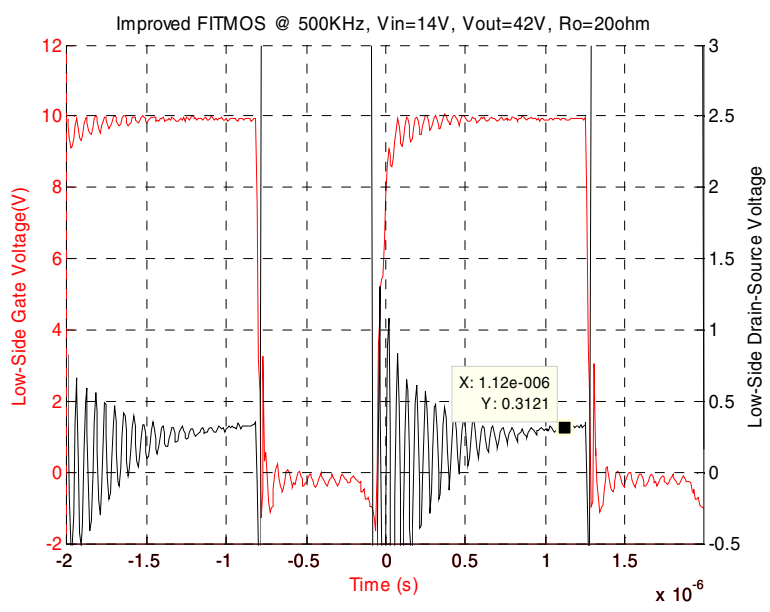

Fig. 13. A sample of the $\mathrm{V}_{\mathrm{ds}}$ measurement under soft-switching at $500 \mathrm{kHz}$. An inductor value of $16 \mathrm{uH}$ was used in the converter.

Two aspects of the dynamic on-resistance behavior are investigated: one is the on-resistance dependence on current frequency (at constant di/dt); the other is the on-resistance dependence on dynamic current change di/dt (at constant drive frequency). The experimental setup is shown in Fig. 14.

A $10 \mathrm{~V} \mathrm{~V}_{\mathrm{gs}}$ is continuously applied to the device to maintain the MOSFET on during the whole experiment. In this way, we can prevent the parasitic ringing from affecting our measurement during the switching transition of the device. A RF power amplifier is used to provide a sinusoidal current through the device. A $50 \Omega$ load is connected in series with the MOSFET to match the output impedance desired by the power amplifier. By measuring the drain-source voltage $V_{d s}$, drain-source current $I_{d s}$ and the phase $\theta$ between $V_{d s}$ and $I_{\mathrm{ds}}$, we can extract the real on-resistance in the MOSFET from $\mathrm{V}_{\mathrm{ds}} / \mathrm{I}_{\mathrm{ds}} * \cos (\theta)$, if the voltage and current waveform are purely sinusoidal with negligible distortion. Measurement data is taken 5 minutes after the system is turned on and reaches thermal steady-state. The MOSFET is mounted to a heatsink to reduce the temperature variation effect on the result. Since the testing current is relative low and the power dissipation of the device is small, temperature variation effect on the on-resistance should be negligible.

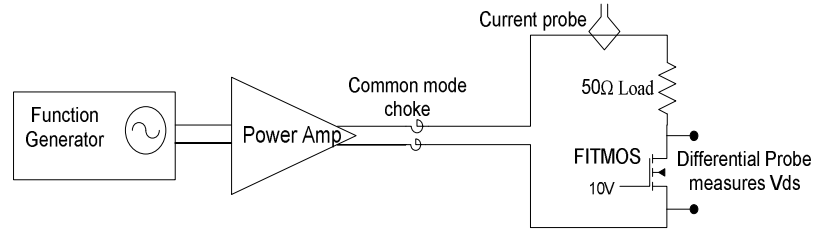

Fig. 14. Equipmental setup for the dynamic on-resistance measurement. A RF power amplifier ENI 3100LA is used to drive the MOSFET.

summary of the experimental results is shown in Fig. 15 and Fig. 16.

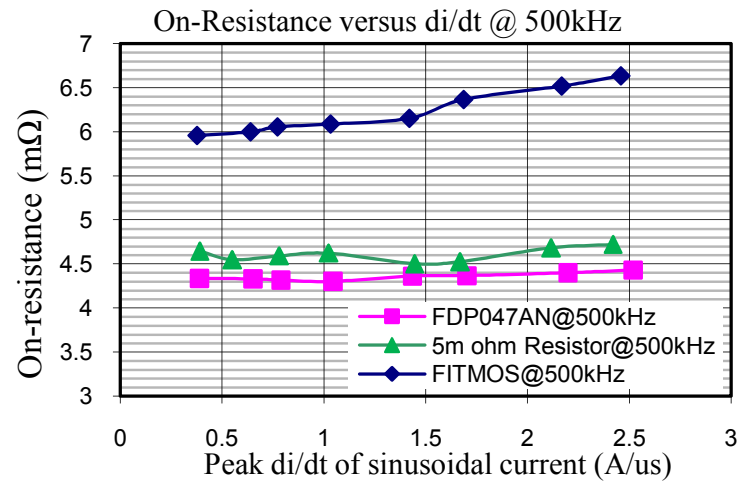

Fig. 15. On resistance variation under different peak di/dt with a given frequency.

On-Resistance versus Frequency with constant di/dt (FITMOS)

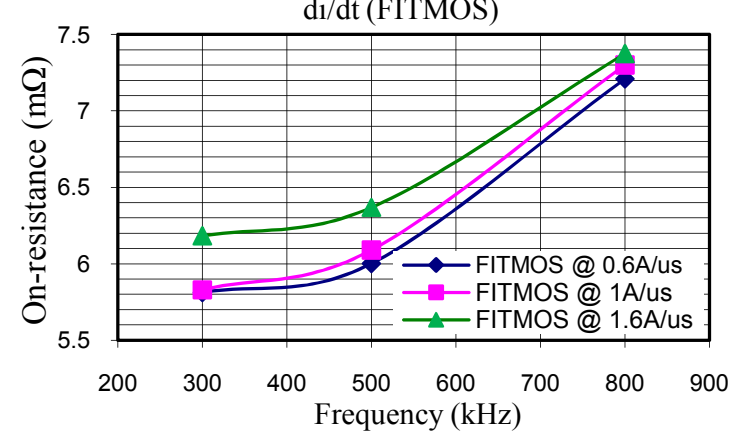

Fig. 16. On resistance versus different drain-source current frequency with constant peak di/dt. 
For comparison, we also include test results for a commercial MOSFET FDP047AN and a simple $5 \mathrm{~m} \Omega$ current sensing resistor. Under $500 \mathrm{kHz}$ sinusoidal current, regardless the peak di/dt, the on-resistance of the commercial device FDP047AN and the resistance of the current sensing resistor remain constant. As shown in Fig. 15, however, the onresistance of the FITMOS device increases $10 \%$ when the peak di/dt increases from $0.4 \mathrm{~A} / \mathrm{us}$ to $2.5 \mathrm{~A} / \mathrm{us}$. In addition, the FITMOS on-resistance also increases with higher frequency with constant di/dt as illustrated in Fig. 16. As a result, the conduction loss of the FITMOS increases with higher $\mathrm{di} / \mathrm{dt}$ and switching frequency. This dynamic on-resistance variation will cause increasing discrepancies between expected performance in simulation and measurement as $\mathrm{di} / \mathrm{dt}$ and switching frequency increase. Even though the softswitching technique can eliminate the switching loss for the devices, the extra conduction loss due to the larger on-state resistance in FITMOS under the high di/dt condition in the "resonant pole" soft-switching offsets the gain. FITMOS has a very competitive low DC on-resistance compared to commercial power MOSFETs of similar blocking voltage $\left(\mathrm{R}_{\mathrm{on}}=5 \mathrm{~m} \Omega @ 25^{\circ} \mathrm{C}, \mathrm{V}_{\mathrm{GS}}=10 \mathrm{~V}\right.$ and $\left.\mathrm{V}_{\mathrm{DSS}}=80 \mathrm{~V}\right)$. However, in order to maintain FITMOS's competitive performance, its onresistance $\mathrm{AC}$ characteristic has to be considered during the converter design process. The advantage of going for a higher $\mathrm{di} / \mathrm{dt}$ in some converter topologies has to overcome the loss from the increased on-resistance.

\section{CONCLUSION}

This paper presents detailed modeling of novel FITMOS transistors. We modeled device capacitance, on state behavior and diode reverse recovery. The resulting behavioral SPICE model shows accurate device performance prediction with respect to experimental measurements in a prototype $14 \mathrm{~V}$-to$42 \mathrm{~V}$ boost converter. However, discrepancies between the simulation and measurement arise at high operating frequency and ripple current. These discrepancies can be explained by the previously unrecognized dynamic characteristic of the on-state resistance in the FITMOS. With the detailed characterization, we can identify how to best utilize the FITMOS characteristics to benefit power circuit design and quantify the gains that can be achieved through their use.

\section{REFERENCES}

[1] K. Miyagi; H. Takaya; H. Saito; K. Hamad, "Floating Island and Thick Bottom Oxide Trench Gate MOSFET (FITMOS) Ultra-Low OnResistance Power MOSFET for Automotive Applications," Power Conversion Conference - Nagoya, 2007. PCC '07, vol., no., pp.10111016, 2-5 April 2007

[2] H. Takaya; K. Miyagi; K. Hamada; Y. Okura; N. Tokura; A. Kuroyanagi, "Floating island and thick bottom oxide trench gate MOSFET (FITMOS) - a 60V ultra low on-resistance novel MOSFET with superior internal body diode," Power Semiconductor Devices and
ICs, 2005. Proceedings. ISPSD '05. The 17th International Symposium on, vol., no., pp. 43-46, 23-26 May 2005

[3] A Q. Huang, "New Unipolar Switching Power Device Figures of Merit", IEEE Electron Device Letters, Vol.25, NO.5, MAY 2004

[4] "JEDEC Standard for Silicon Rectifier Diodes", JESD282B.01, JEDEC Solid State Technology Association, November 2002

[5] "Test Method Standard Semiconductor Devices", MIL-STD-750D, Method 4031.3, Department of Defense, February, 1983

[6] D A. Hodges; H G. Jackson, "Analysis and Design of Digital Integrated Circuits," New York: McGraw-Hill, 1983, pp. 147-149 